\title{
An Initial Open-Label Study of a Novel Pheromone Complex for Use in Cats
}

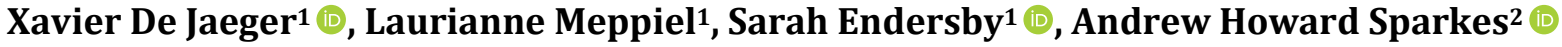 \\ ${ }^{1}$ CEVA Santé Animale, Libourne, France \\ ${ }^{2}$ Simply Feline Veterinary Consultancy, Shaftesbury, Dorset, UK \\ Email: andy@simplyfeline.net
}

How to cite this paper: De Jaeger, X., Meppiel, L., Endersby, S. and Sparkes, A.H. (2021) An Initial Open-Label Study of a Novel Pheromone Complex for Use in Cats. Open Journal of Veterinary Medicine, 11, 105-116.

https://doi.org/10.4236/ojvm.2021.113006

Received: March 9, 2021

Accepted: March 27, 2021

Published: March 30, 2021

Copyright (c) 2021 by author(s) and Scientific Research Publishing Inc. This work is licensed under the Creative Commons Attribution International License (CC BY 4.0).

http://creativecommons.org/licenses/by/4.0/

\begin{abstract}
Background: A number of specific synthetic pheromones have been commercially available for many years and used to help modify different problem behaviours exhibited by companion animals. Recently, a new synthetic feline pheromone complex has been patented and made available commercially. Objectives: This study was designed as an initial open-label uncontrolled trial to evaluate the potential impact of the new synthetic pheromone complex on a range of different problem behaviours in pet cats. Methods: 150 owned pet cats from either one-cat $(n=66)$ or two-cat $(n=84)$ households that had one or more of four defined problem behaviours (urine spraying, $n=31$; scratching furnishings, $\mathrm{n}=113$; fear, $\mathrm{n}=63$; or inter-cat conflict, $\mathrm{n}=25$ ), were recruited to a 28-day study of a new plug-in diffuser containing the novel feline pheromone complex. Results: By day 28, significant ( $\mathrm{P}$ values $\leq 0.01$ ) improvements were seen in both the frequency and intensity of all four problem behaviours, as assessed by the owners using blinded questionnaires. A reduction in the frequency of individual problem behaviours was reported by $69.8 \%-77.4 \%$ of owners and a reduction in the intensity of the problem by $64.0 \%-74.2 \%$. Conclusions: The results of this study support the concept that the new feline pheromone complex may have the ability to address multiple problem behaviours. Nevertheless, further controlled studies will be necessary and important to both confirm, and to fully assess the clinical efficacy of the product.
\end{abstract}

\section{Keywords}

Cats, Pheromones, Behaviour, Spraying, Scratching, Fear, Conflict

\section{Introduction}

Feline problem behaviours are behaviours that are generally considered normal 
for the cat, but become a problem for the owner or person who lives with the cat [1], and modern lifestyles (including keeping cats primarily or exclusively indoors) may be one of the reasons that problem behaviours occur [2]. Common feline problem behaviours reported in the literature include anxiety/fears, aggression towards other cats or humans, inappropriate elimination, furniture scratching, vocalisation, compulsive behaviours, pica, overactivity and hunting [1]-[7]. The prevalence of different problem behaviours varies between study populations and methodologies [2], and the reasons for the problem behaviours are also diverse. Control of problem behaviours requires careful evaluation of the cat, its background and environment, along with an integrated approach to management that often includes the use of synthetic pheromones [4] [8] [9].

Mammalian pheromones are semiochemicals detected primarily by the vomeronasal organ (VNO) through specialised receptors, and they induce innate behavioural responses which are generally employed for intra-species communication. Pheromones may communicate a variety of physiological and behavioural states such as sexual receptiveness, fear, alarm, safety, appeasement and territorial marking, and serve as cues to trigger behaviour in conspecifics [10] [11] [12] [13]. The diversity of VNO receptors varies greatly between species [14] [15] [16] [17], and cats have an appreciably larger VNO receptor repertoire compared with dogs, suggesting they have a greater reliance on pheromone-mediated communication [18].

A number of patented synthetic pheromones have been developed for use in cats including a feline facial pheromone (FFP, specifically the F3 FFP fraction which is thought to be deposited in the environment during facial rubbing of objects and convey a sense of security and reduced stress), a cat appeasing pheromone $(\mathrm{CAP}$ - released by the queen during nursing and thought to enhance inter-cat bond formation and security), and a feline interdigital semiochemical (FIS-thought to be deposited on objects during environmental scratching behaviour) [9] [11] [19]. Since 1996, various commercial products have become available (respectively FELIWAY ${ }^{\circledR}$ Classic, FELIWAY ${ }^{\circledR}$ Friends, and Feliscratch ${ }^{\circledR}$, Ceva Santé Animale) based on these synthetic pheromones, and have been successfully used as an aid to managing stress (e.g., anxiety or frustration), intra-species conflict, and other undesirable behavioural problems [9] [11] [19].

Recently, the same group that developed the synthetic feline (and canine) pheromones evaluated feline VNO receptor binding sites for pheromones through computational modeling [20], and as a result, have patented a new complex of synthetic pheromone molecules designed to address a broader range of behavioural modifications with a single product. The novel complex is a mix of specific synthetic pheromone molecules at a specific ratio, chosen for their high affinity for VNO VR1 receptors via in silico binding studies. [20] This new complex is now available as a proprietary plug-in diffuser (FELIWAY ${ }^{\circledR}$ Optimum, Ceva Santé Animale) [21].

The current study was designed as a preliminary evaluation of the new commercial product (FELIWAY ${ }^{\circledR}$ Optimum, Ceva Santé Animale) in a substantial 
number of owned cats in the USA exhibiting one or more of four common defined problem behaviours, as an open-label initial study to explore the product's efficacy.

\section{Methods}

\subsection{Study Population}

The study population was derived from a proprietary database of cat owners living in the USA. Inclusion criteria were that the owner had to have either one or two cats living in the house, both between 6 months and 12 years of age, and at least one cat had to be exhibiting at least one of four specified problem behaviours:

- Problem urination (defined as urinating away from the litter box indoors while in a standing position and against a vertical surface-this definition was chosen to minimise the likelihood of confusion between behavioural urine marking and periuria associated with lower urinary tract disease [22] [23]);

- Problem scratching (defined as scratching vertical surfaces indoors, other than scratching posts, such as sofas, carpets, and curtains);

- Problem fear (defined as fearful behaviour such as hiding in response to visitors, unusual or loud noises, unusual situations, etc.);

- Problem inter-cat conflict (defined as signs of conflict, fighting, intimidation between cats when indoors and when there were two cats in the household). Additional inclusion criteria were that there had to be a minimum of one litterbox and one scratching post per cat in the house. Cats and households were excluded if:

- any pheromones or other calming products (including nutraceuticals) had been used within the preceding 6 months;

- there was any current veterinary diagnosed medical problem(s) with the $\operatorname{cat}(\mathrm{s})$;

- one or both cats had stayed away from the home (for any length of time) within the previous 15 days, and;

- the owner anticipated being away from home for more than 2 days during the study period.

The aim was to recruit a minimum of 150 cats into the study.

\subsection{Study Design}

Owners were asked to complete an on-line questionnaire which included details of the cat(s) and questions to confirm eligibility. Specific information about the problem behaviour(s) was obtained (day 0) comprising:

1) The duration of the problem behavior.

2) The frequency of the problem behaviour assigned as to a 7-point numerical scale as: a) Less than once a week; b) Once a week; c) Twice a week; d) Every two days; e) Almost every day; f) Once or twice daily, OR; g) Several times daily. 
3) The perceived intensity (or severity) of the problem, evaluated on a visual analogue scale (VAS) from 0 (extremely low) to 10 (extremely high).

4) The owner was asked to respond to the statements a) "I am concerned about the impact of the specific problem behaviour on my home" and b) "I am concerned about my cat's own wellbeing based on their habits", with a 6-point numerical scale scored from 1 "strongly disagree" with the statement, to 6 "strongly agree".

Owners were asked to plug a pheromone diffuser (FELIWAY ${ }^{\circ}$ Optimum) directly into a wall socket in the room in the house where their cat(s) spent the largest amount of time and to keep it on throughout the 28-day study period. Only one room was allowed in each house and a green LED indicator light was incorporated into the diffuser to confirm it was working. Owners were not asked to make any other changes to their routines or their care of the cat(s).

After 7 and 28 days, owners were asked to complete a repeat on-line questionnaire, designed to check whether the diffuser was still being used and functioning properly, and to collect repeat information about the problem behaviours using the same questions as day 0 . Repeat questionnaires were performed blind (owners did not have access to their previous answers), and any non-responders were contacted directly to ensure completion of questionnaires.

\subsection{Statistical Analysis}

The primary endpoints of the study were the assessment of owner-reported frequency and intensity of the problem behaviours at day 28 compared with day 0 . Secondary endpoints were evaluation of the concern of the owners about the impact of the behaviour on their home and the cat's wellbeing, and evaluation of data collected at day 7 compared with day 0 .

Data are reported as median values (along with the minimum, maximum and inter-quartile ranges IQR). Comparison between time points (days 0, 7 and 28) was performed with a Friedman Test, and where a significant difference was found Dunn's multiple comparisons test was used to identify which day(s) differed significantly from day 0 . Differences in proportions of cats responding (between a single cat and two-cat households) were assessed with a Chi-squared or Fisher's exact test as appropriate and differences in magnitude of responses between these two groups were assessed with the Mann Whitney U test. A P value of $<0.05$ was considered significant.

\section{Results}

A total of 122 owners were recruited who met the inclusion and exclusion criteria. Of these, data from 14 owners were excluded for the following reasons: the power light on the diffuser turned off before day 26 or turned off intermittently $\geq 3$ times during the study $(\mathrm{n}=10)$, the owner did not like the smell $(\mathrm{n}=2)$, was concerned about potential risks $(n=1)$ or because the cat was behaving differently $(\mathrm{n}=1)$. Of the 108 households that completed the study, 42 owned two 
cats, and 66 owned a single cat, giving a total of 150 cats. No other problems were reported except that eight owners reported that the power light turned off on or after day 26 of the study, and nine reported that the power light had turned off intermittently on one or two occasions during the study-data from these cases were included in the analysis.

The median age of the 150 cats was 3 years old (range 0.5 - 12, IQR 2 - 5). Their median weight was $4.5 \mathrm{~kg}$ (range 1 - $15 \mathrm{~kg}$, IQR $4.1-6.4 \mathrm{~kg}$ ). There were 91 mixed breed (including domestic shorthair and domestic longhair) cats, 9 where the breed was unknown or unstated, and 50 pedigree cats (comprising 20 American shorthair, 13 Siamese, 4 Persian, 3 Bombay, 3 Burmese, 3 Russian Blue, 2 Maine Coon and each of Havana, Singapura and Ragdoll). There were 91 males and 59 females, 51 (86\%) of the females were neutered, but due to a database error, the number of neutered males was not available.

Of the 150 cats, 145 exhibited one or more of the four problem behaviours (there were 5 cats living in two-cat homes where their housemate exhibited unwanted behaviour, but they did not). Of the 145 cats with problem behaviours, 75 exhibited a single problem behaviour, 53 exhibited two and 17 exhibited three. Overall, there were 31 cats with problem urination, 63 with fear, 113 with scratching and 25 with inter-cat conflict. Where reported, the median duration of problem behaviours was 12 months for problem urination (range 1 - 84, IQR 5 - 24, $\mathrm{n}=28$ ); 12 months for scratching (range 1 - 120, IQR 6 - 36, n = 92); 24 months for fear (range 1 - 120, IQR $11-36, \mathrm{n}=48$ ); and 24 months for inter-cat conflict (range 3 - 120, IQR $12-48, \mathrm{n}=21$ ).

Summary data for the four problem behaviours are shown in Table 1 and Figure 1 . As can be seen, a significant $(\mathrm{P} \leq 0.01)$ improvement in all primary end-point data (frequency and intensity of problem behaviours) was seen at day 28 , with $\geq 69.8 \%$ of cats showing improvement in the frequency and $\geq 64.0 \%$ improvement in the intensity of the problem. Additionally, a smaller improvement was evident in all parameters at day 7 (a secondary end point), which was significant in five of the eight parameters. With the exception of cats displaying problem urination, there were also significant $(\mathrm{P} \leq 0.004)$ improvements in the owner-perceived impact of the problem behaviours on day 28. Comparing the data for problem fear, urination and scratching, there was no significant difference in the proportion of cats that improved or the magnitude of the response (for either frequency or intensity of the problems) between cats in single-cat households and those in two-cat households.

In addition to the data shown in Table 1, a simple overall "Index score" was calculated for the four problem behaviours by multiplying values obtained for the frequency and intensity scores. Median Index scores at days 0, 7 and 28 were: $33.5,14.4$ and 5.3 for problem urination; 38.5, 21.2, and 8.3 for problem scratching; 33.0, 20.4 and 8.5 for problem fear; and 42.7, 32.5, and 9.2 for problem inter-cat conflict. The reductions in the Index scores at day 28 were all significant compared with day $0(\mathrm{P}<0.001)$ and were also significantly lower at day 7 $(\mathrm{P} \leq 0.005)$ with the exception of the inter-cat conflict. 


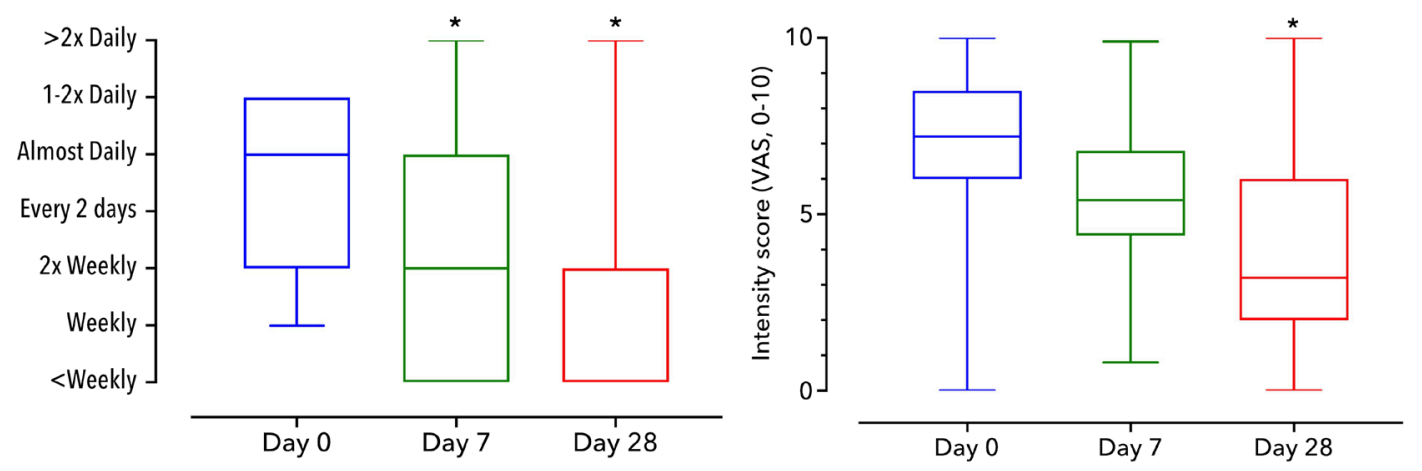

(a)
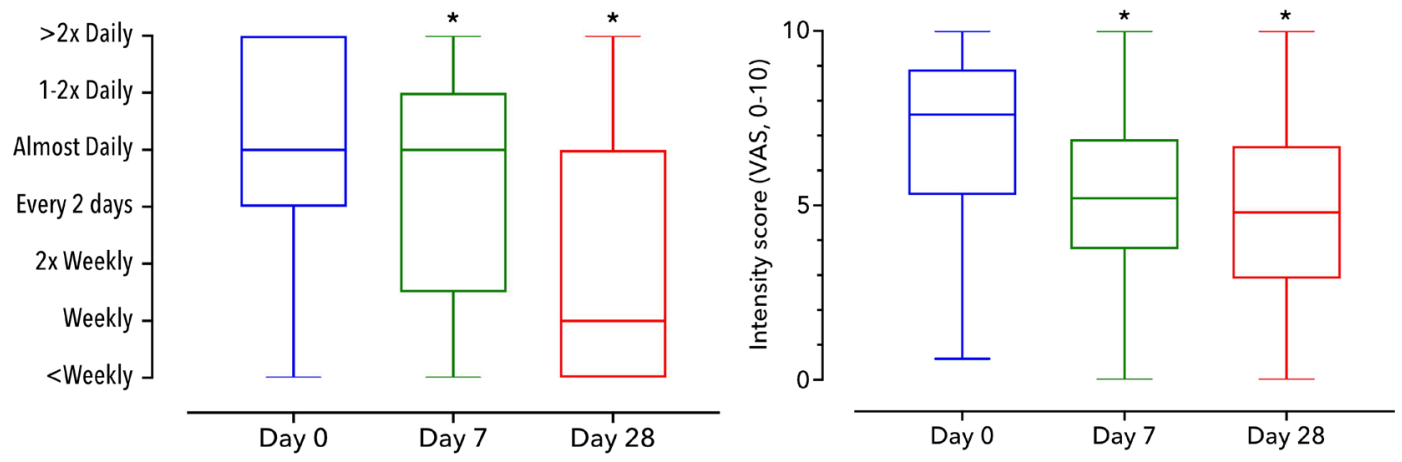

(b)
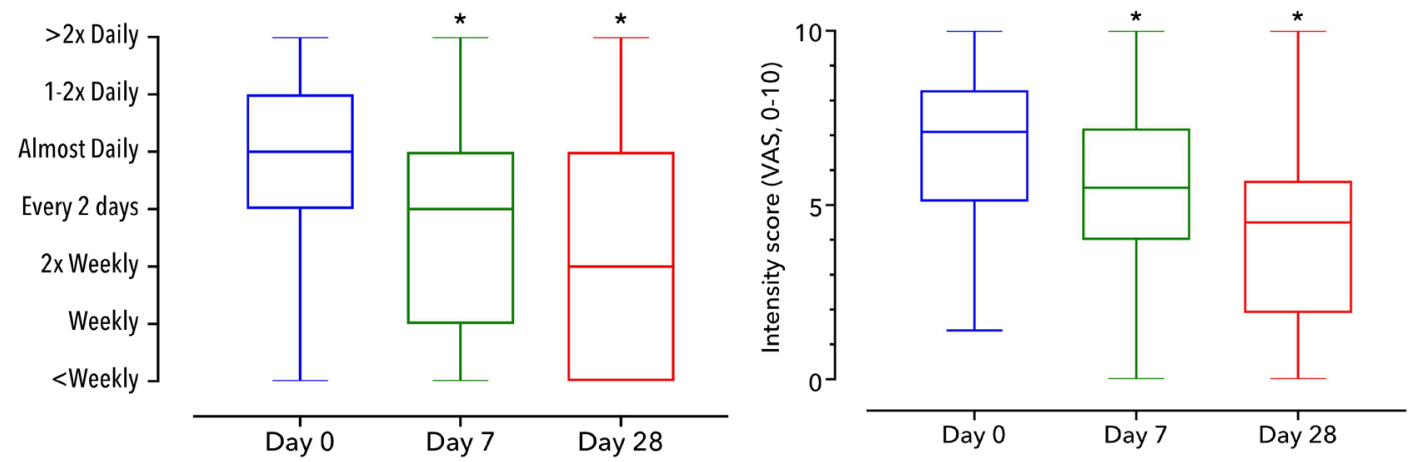

(c)
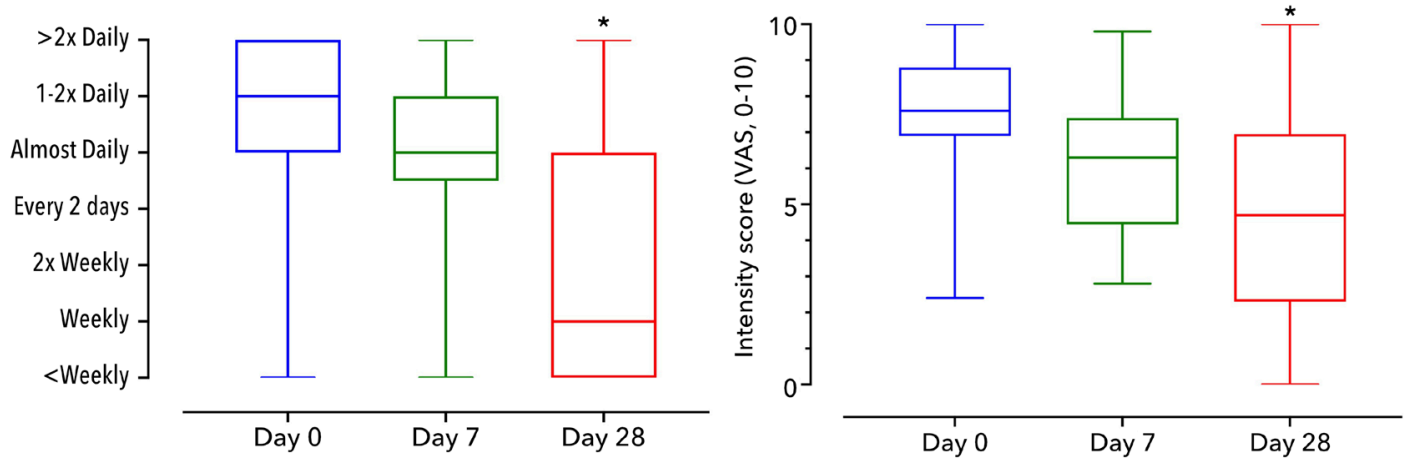

(d)

Figure 1. Box \& Whisker plots showing median (range, IQR) of frequency (left) and intensity (right) of the four problem behaviours during the study. (a) Problem urination; (b) Problem scratching; (c) Problem fear; (d) Problem inter-cat conflict; ${ }^{\star}=$ significantly different from day 0; VAS = Visual analogue Scale. 
Table 1. Summary data for owner evaluation of four problem behaviours during the course of the study, showing median (range, IQR) values for assessments.

\begin{tabular}{|c|c|c|c|c|c|}
\hline Problem and evaluation & Day 0 & Day 7 & Day 28 & $P^{*}$ & $\begin{array}{c}\% \text { improved } \\
\text { D0 } \rightarrow \text { D28 }\end{array}$ \\
\hline \multicolumn{6}{|c|}{ Problem urination $(\mathrm{n}=31)$} \\
\hline Frequency $^{\mathrm{a}}$ & $\begin{array}{c}5.0 \\
(2-6,3-6)\end{array}$ & $\begin{array}{c}3.0^{\sharp} \\
(1-7,1-5)\end{array}$ & $\begin{array}{c}1.0^{\sharp} \\
(1-7,1-3)\end{array}$ & $\mathrm{P}<0.001$ & $77.4 \%$ \\
\hline Intensity ${ }^{\mathrm{b}}$ & $\begin{array}{c}7.2 \\
(0-10,6.0-8.5)\end{array}$ & $\begin{array}{c}5.4 \\
(0.8-9.9,4.4-6.8)\end{array}$ & $\begin{array}{c}3.2^{*} \\
(0-10,2.0-6.0)\end{array}$ & $\mathrm{P}=0.001$ & $74.2 \%$ \\
\hline Impact on the house ${ }^{c}$ & $\begin{array}{c}5.0 \\
(1-6,4-6)\end{array}$ & $\begin{array}{c}5.0 \\
(1-6,4-6)\end{array}$ & $\begin{array}{c}5.0 \\
(1-6,3-6)\end{array}$ & $\mathrm{P}=0.43$ & $41.9 \%$ \\
\hline Impact on the cat ${ }^{c}$ & $\begin{array}{c}5.0 \\
(2-6,4-6)\end{array}$ & $\begin{array}{c}5.0 \\
(1-6,4-6)\end{array}$ & $\begin{array}{c}5.0 \\
(1-6,3-6)\end{array}$ & $\mathrm{P}=0.17$ & $51.6 \%$ \\
\hline \multicolumn{6}{|c|}{ Problem scratching $(\mathrm{n}=113)$} \\
\hline Frequency $^{\mathrm{a}}$ & $\begin{array}{c}5.0 \\
(1-7,4-7)\end{array}$ & $\begin{array}{c}5.0^{\sharp} \\
(1-7,2.5-6)\end{array}$ & $\begin{array}{c}2.0^{\sharp} \\
(1-7,1-5)\end{array}$ & $\mathrm{P}<0.001$ & $73.5 \%$ \\
\hline Intensity ${ }^{\mathrm{b}}$ & $\begin{array}{c}7.6 \\
(0.6-10,5.3-8.9)\end{array}$ & $\begin{array}{c}5.2^{*} \\
(0-10,3.8-6.9)\end{array}$ & $\begin{array}{c}4.8^{*} \\
(0-10,2.9-6.7)\end{array}$ & $\mathrm{P}<0.001$ & $68.1 \%$ \\
\hline Impact on the house ${ }^{c}$ & $\begin{array}{c}5.0 \\
(1-6,4.5-6)\end{array}$ & $\begin{array}{c}5.0^{*} \\
(1-6,4-6)\end{array}$ & $\begin{array}{c}4.0^{*} \\
(1-6,3-6)\end{array}$ & $\mathrm{P}<0.001$ & $50.4 \%$ \\
\hline Impact on the cat ${ }^{c}$ & $\begin{array}{c}5.0 \\
(1-6,4-6)\end{array}$ & $\begin{array}{c}4.0^{\#} \\
(1-6,3-6)\end{array}$ & $\begin{array}{c}4 . O^{\sharp} \\
(1-6,3-5)\end{array}$ & $\mathrm{P}<0.001$ & $59.3 \%$ \\
\hline \multicolumn{6}{|c|}{ Problem fear $(n=63)$} \\
\hline Frequency $^{a}$ & $\begin{array}{c}5.0 \\
(1-7,4-6)\end{array}$ & $\begin{array}{c}4.0^{*} \\
(1-7,2-5)\end{array}$ & $\begin{array}{c}3.0^{\sharp} \\
(1-7,1-5)\end{array}$ & $\mathrm{P}<0.001$ & $69.8 \%$ \\
\hline Intensity ${ }^{\mathrm{b}}$ & $\begin{array}{c}7.1 \\
(1.4-10,5.1-8.3)\end{array}$ & $\begin{array}{c}5.5^{\sharp} \\
(0-10,4.0-7.2)\end{array}$ & $\begin{array}{c}4.5^{\#} \\
(0-10,1.9-5.7)\end{array}$ & $\mathrm{P}<0.001$ & $71.4 \%$ \\
\hline Impact on the house ${ }^{c}$ & $\begin{array}{c}5.0 \\
(1-6,4-6)\end{array}$ & $\begin{array}{c}4.0 \\
(1-6,3-6)\end{array}$ & $\begin{array}{c}3.0^{*} \\
(1-6,2-5)\end{array}$ & $\mathrm{P}<0.001$ & $54.0 \%$ \\
\hline Impact on the $\mathrm{cat}^{\mathrm{c}}$ & $\begin{array}{c}4.0 \\
(1-6,4-6)\end{array}$ & $\begin{array}{c}4.0 \\
(1-6,4-6)\end{array}$ & $\begin{array}{c}2.0^{*} \\
(1-6,2-5)\end{array}$ & $\mathrm{P}=0.004$ & $47.6 \%$ \\
\hline \multicolumn{6}{|c|}{ Problem inter-cat conflict $(\mathrm{n}=25)$} \\
\hline Frequency $^{\mathrm{a}}$ & $\begin{array}{c}6.0 \\
(1-7,5-7)\end{array}$ & $\begin{array}{c}5.0 \\
(1-7,4.5-6)\end{array}$ & $\begin{array}{c}2.0^{*} \\
(1-7,1-5)\end{array}$ & $\mathrm{P}<0.001$ & $72.0 \%$ \\
\hline Intensity ${ }^{\mathrm{b}}$ & $\begin{array}{c}7.6 \\
(2.4-10,6.9-8.8)\end{array}$ & $\begin{array}{c}6.3 \\
(2.8-9.8,4.5-7.4)\end{array}$ & $\begin{array}{c}4.7^{*} \\
(0-10,2.3-7.0)\end{array}$ & $\mathrm{P}=0.011$ & $64.0 \%$ \\
\hline Impact on the house ${ }^{c}$ & $\begin{array}{c}5.0 \\
(1-6,4-6)\end{array}$ & $\begin{array}{c}4.0 \\
(1-6,3-6)\end{array}$ & $\begin{array}{c}4 . O^{\sharp} \\
(1-6,2-5)\end{array}$ & $\mathrm{P}=0.004$ & $64.0 \%$ \\
\hline Impact on the cat ${ }^{c}$ & $\begin{array}{c}5.0 \\
(3-6,4-6)\end{array}$ & $\begin{array}{c}5.0 \\
(1-6,3.5-6)\end{array}$ & $\begin{array}{c}4 . O^{\sharp} \\
(1-6,2-5)\end{array}$ & $\mathrm{P}<0.001$ & $64.0 \%$ \\
\hline
\end{tabular}

${ }^{a}$ Values for Frequency categorical on a scale of $1-7$ (see text); ${ }^{b}$ Values for Intensity continuous (visual analogue scale of $0-10$, see text); ${ }^{c}$ Values for impact on house and cat categorical, scaled 1 - 6 (see text); ${ }^{*}$ P values from Friedman test, Day 0 vs. Day 28 ; ${ }^{*}$ Median value significantly different from day 0 using Dunn's post-test multiple comparison analysis. 


\section{Discussion}

This study, although involving a large number of cats, was only designed to provide initial data on the efficacy of a new synthetic pheromone complex. As such, it was an open-label, uncontrolled study and the results, therefore, need to be treated with appropriate caution. There was evidence of significant improvement in both the frequency and intensity of all four problem behaviours. The greater efficacy at day 28 is consistent with previously controlled studies of both FFP and CAP that suggest the maximal effect of synthetic pheromones used in diffusers may take a few weeks to achieve [24] [25]. While most of the cats included in the current study had long-standing problem behaviours, and while efforts were made to reduce reporting bias by blinding owners to the data they had inputted on previous questionnaires, importantly this study contained no control group and thus any placebo effect, which could be appreciable, cannot be accounted for. This means that the results must be treated with appropriate caution, and future studies should include a control group to fully evaluate the efficacy of the pheromone complex.

We evaluated four common problem behaviours in this study. Previous studies of synthetic CAP have focussed on the improvement of inter-cat conflict, aggression and social tension [19] [24], while studies of synthetic FFP have suggested positive effects on various stress-related behaviours such as problem urination [25] [26] [27] [28], scratching within the home [29], and environmental-induced stress [30] [31]. The results of the current study, with significant improvements in all four problem behaviours, suggest that the new pheromone complex may indeed positively influence a broader range of problem behaviours than has been achieved with previous products, but again, further controlled studies are needed to confirm efficacy. The secondary outcomes of owner-perceived impact of the problem behaviours on their house and on the wellbeing of their cats were designed to collect qualitative rather than quantitative data. Interestingly, these outcomes also all showed significantly improved scores at day 28 , with the exception of scores relating to problem urination (where improvements did not reach significance). The lack of significant improvement with problem urination may perhaps be explained by the fact that persistent inappropriate urination in the house, albeit at a reduced frequency/severity, is still likely to be perceived as a serious problem for owners and may also reflect the relatively small number of cats with problem urination.

Quantifying either the frequency or severity of behavioural problems in the home setting is inherently problematic. Both rely on owner observations and perceptions which may readily vary between individual owners. However, these limitations can be mitigated (at least to some extent) by conducting longitudinal studies (as in this case) where responses to an intervention are reported by the same owners over time, and by using a large number of subjects. We evaluated an "Index score" by combining (multiplying) results of the frequency and intensity scores in an attempt to provide a single score that took into account both 
these factors. While this is an attractive way to quantify the problem, in our study owners were not specifically asked to ignore the frequency of the problem when they were scoring the intensity, which may have conflated the results, so the Index score should be interpreted with caution and this should be addressed in future studies.

The absence of methods to directly and objectively measure the biological effects of synthetic pheromones in companion animals means that, as in this study, effects have to be inferred from changes seen in observed behaviours. Although many published studies have shown significant benefits from the use of synthetic pheromones (including a meta-analysis of studies on urine spraying [28]), it should be noted that is not true of all publications, as highlighted in a systematic review [32] (although the methodology in the systematic review may itself have been flawed including incorrect data analyses and comparison, and false assumptions that active ingredients other than synthetic pheromones were included in studies of diffusers [33] [34]). Nevertheless, it would be surprising if variable results were not found in publications as different studies have evaluated pheromones in different circumstances and situations and, however a pheromone signal is perceived by an animal, there are many external factors that might influence or even override any potential physiological and behavioural responses induced. The use of synthetic pheromones as therapy for problem behaviours, unlike the current study, is therefore generally recommended only as part of a wider integrated approach to behaviour management [8] [9] [19].

In summary, this open-label uncontrolled study suggested a significant influence of a new proprietary synthetic pheromone complex product on four common feline problem behaviours, indicating the product may possess broad behaviour-modifying properties. However, this can only be regarded as an initial study and further evaluation of the product in a controlled clinical trial will be needed and important to confirm its efficacy and quantify any placebo effect that may play a role in apparent responses to intervention.

\section{Acknowledgements}

The authors thank Khnata Lamchemmach for organising product logistics and transport.

This research was conducted by Ceva Santé Animale. Xavier De Jaeger, Laurianne Meppiel and Sarah Endersby are employees of Ceva Santé Animale.

\section{Conflicts of Interest}

The authors declare no conflicts of interest regarding the publication of this paper.

\section{References}

[1] Curtis, T.M. (2020) Behavior Problem or Problem Behavior. Veterinary Clinics of North America: Small Animal Practice, 50, 707-718.

https://doi.org/10.1016/j.cvsm.2020.03.002 
[2] Amat, M., de la Torre, J.L.R., Fatjó, J., Mariotti, V.M., Van Wijk, S. and Manteca, X. (2009) Potential Risk Factors Associated with Feline Behaviour Problems. Applied Animal Behaviour Science, 121, 134-139. https://doi.org/10.1016/j.applanim.2009.09.012

[3] Bamberger, M. and Houpt, K.A. (2006) Signalment Factors, Comorbidity, and Trends in Behavior Diagnoses in Cats: 736 Cases (1991-2001). Journal of the American Veterinary Medical Association, 229, 1602-1606. https://doi.org/10.2460/javma.229.10.1602

[4] Bradshaw, J. (2018) Normal Feline Behaviour: ... and Why Problem Behaviours Develop. Journal of Feline Medicine and Surgery, 20, 411-421. https://doi.org/10.1177/1098612X18771203

[5] Fatjó, J., Ruiz-De-La-Torre, J.L. and Manteca, X. (2006) The Epidemiology of Behavioural Problems in Dogs and Cats: A Survey of Veterinary Practitioners. Animal Welfare, 15, 179-185.

[6] Tamimi, N., Malmasi, A., Talebi, A., Tamimi, F. and Amini, A. (2015) A Survey of Feline Behavioral Problems in Tehran. Veterinary Research Forum, 6, 143-147.

[7] Yamada, R., Kuze-Arata, S., Kiyokawa, Y. and Takeuchi, Y. (2020) Prevalence of 17 Feline Behavioral Problems and Relevant Factors of each Behavior in Japan. The Journal of Veterinary Medical Science, 82, 272-278.

[8] Hammerle, M., Horst, C., Levine, E., et al. (2015) 2015 AAHA Canine and Feline Behavior Management Guidelines. Journal of the American Animal Hospital Association, 51, 205-221. https://doi.org/10.5326/JAAHA-MS-6527

[9] Vitale, K.R. (2018) Tools for Managing Feline Problem Behaviors: Pheromone therapy. Journal of Feline Medicine and Surgery, 20, 1024-1032. https://doi.org/10.1177/1098612X18806759

[10] Morozov, A. and Ito, W. (2019) Social Modulation of Fear: Facilitation vs. Buffering. Genes, Brain and Behavior, 18, e12491.https://doi.org/10.1111/gbb.12491

[11] Pageat, P. and Gaultier, E. (2003) Current Research in Canine and Feline Pheromones. Veterinary Clinics of North America: Small Animal Practice, 33, 187-211. https://doi.org/10.1016/S0195-5616(02)00128-6

[12] Papes, F., Logan, D.W. and Stowers, L. (2010) The Vomeronasal Organ Mediates Interspecies Defensive Behaviors through Detection of Protein Pheromone Homologs. Cell, 141, 692-703. https://doi.org/10.1016/j.cell.2010.03.037

[13] Stowers, L. and Kuo, T.H. (2015) Mammalian Pheromones: Emerging Properties and Mechanisms of Detection. Current Opinion in Neurobiology, 34, 103-109. https://doi.org/10.1016/j.conb.2015.02.005

[14] Nikaido, M. (2019) Evolution of V1R Pheromone Receptor Genes in Vertebrates: Diversity and Commonality. Genes \& Genetic Systems, 94, 141-149.

[15] Rodriguez, I. (2005) Remarkable Diversity of Mammalian Pheromone Receptor Repertoires. Proceedings of the National Academy of Sciences of the United States of America, 102, 6639-6640. https://doi.org/10.1073/pnas.0502318102

[16] Rouquier, S. and Giorgi, D. (2007) Olfactory Receptor Gene Repertoires in Mammals. Mutation Research, 616, 95-102. https://doi.org/10.1016/j.mrfmmm.2006.11.012

[17] Young, J.M., Massa, H.F., Hsu, L. and Trask, B.J. (2010) Extreme Variability among Mammalian V1R Gene Families. Genome Research, 20, 10-18. https://doi.org/10.1101/gr.098913.109

[18] Montague, M.J., Li, G., Gandolfi, B., et al. (2014) Comparative Analysis of the Do- 
mestic Cat Genome Reveals Genetic Signatures Underlying Feline Biology and Domestication. Proceedings of the National Academy of Sciences of the United States of America, 111, 17230-17235. https://doi.org/10.1073/pnas.1410083111

[19] Prior, M.R. and Mills, D.S. (2020) Cats vs. Dogs: The Efficacy of Feliway Friends and Adaptil Products in Multispecies Homes. Frontiers in Veterinary Science, 7, 399. https://doi.org/10.3389/fvets.2020.00399

[20] Durairaj, R., Bienboire-Frosini, C., Cozzi, A. and Pageat, P. (2020) Sequence Analysis and Multi-Template Threading of Cat Vomeronasal Type-1 Receptor with an Evaluation of Feline Semiochemical Interactions Using Virtual Screening (Abstract). Chemical Senses, 45, 145. https://doi.org/10.1093/chemse/bjaa007

[21] Pageat, P. (2020) The Whole Story of Discovery and a New Step in Pheromonatherapy. Proceedings of the ISFM International Congress, International Society of Feline Medicine on-line Congress, 8-10 August 2020, 120-122.

https://icatcare.org/veterinary/isfm/

[22] Horwitz, D.F. (2019) Common Feline Problem Behaviors: Urine Spraying. Journal of Feline Medicine and Surgery, 21, 209-219.

https://doi.org/10.1177/1098612X19831203

[23] Tynes, V.V., Hart, B.L., Pryor, P.A., Bain, M.J. and Messam, L.L. (2003) Evaluation of the Role of Lower Urinary Tract Disease in Cats with Urine-Marking Behavior. Journal of the American Veterinary Medical Association, 223, 457-461. https://doi.org/10.2460/javma.2003.223.457

[24] DePorter, T.L., Bledsoe, D.L., Beck, A. and Ollivier, E. (2019) Evaluation of the Efficacy of an Appeasing Pheromone Diffuser Product vs. Placebo for Management of Feline Aggression in Multi-Cat Households: A Pilot Study. Journal of Feline Medicine and Surgery, 21, 293-305. https://doi.org/10.1177/1098612X18774437

[25] Ogata, N. and Takeuchi, Y. (2001) Clinical Trial of a Feline Pheromone Analogue for Feline Urine Marking. The Journal of Veterinary Medical Science, 63, 157-161.

[26] Frank, D.F., Erb, H.N. and Houpt, K.A. (1999) Urine Spraying in Cats: Presence of Concurrent Disease and Effects of a Pheromone Treatment. Applied Animal Behaviour Science, 61, 263-272. https://doi.org/10.1016/S0168-1591(98)00195-6

[27] Mills, D.S. and Mills, C.B. (2001) Evaluation of a Novel Method for Delivering a Synthetic Analogue of Feline Facial Pheromone to Control Urine Spraying by Cats. Veterinary Record, 149, 197-199. https://doi.org/10.1136/vr.149.7.197

[28] Mills, D.S., Redgate, S.E. and Landsberg, G.M. (2011) A Meta-Analysis of Studies of Treatments for Feline Urine Spraying. PLOS ONE, 6, e18448.

https://doi.org/10.1371/journal.pone.0018448

[29] DePorter, T.L. and Elzerman, A.L. (2019) Common Feline Problem Behaviors: Destructive Scratching. Journal of Feline Medicine and Surgery, 21, 235-243. https://doi.org/10.1177/1098612X19831205

[30] da Silva, B.P.L., Knackfuss, F.B., Labarthe, N. and Mendes-de-Almeida, F. (2017) Effect of a Synthetic Analogue of the Feline Facial Pheromone on Salivary Cortisol Levels in the Domestic Cat. Pesquisa Veterinária Brasileira, 37, 287-290. https://doi.org/10.1590/s0100-736x2017000300013

[31] Griffith, C.A., Steigerwald, E.S. and Buffington, C.A. (2000) Effects of a Synthetic Facial Pheromone on Behavior of Cats. Journal of the American Veterinary Medical Association, 217, 1154-1156. https://doi.org/10.2460/javma.2000.217.1154

[32] Frank, D., Beauchamp, G. and Palestrini, C. (2010) Systematic Review of the Use of Pheromones for Treatment of Undesirable Behavior in Cats and Dogs. Journal of the American Veterinary Medical Association, 236, 1308-1316. 
https://doi.org/10.2460/javma.236.12.1308

[33] Beck, A. (2010) Questions Study on the Use of Pheromones in Dogs and Cats. Journal of the American Veterinary Medical Association, 237, 493-496.

[34] Pageat, P. (2010) Questions Methods Used in Review of Pheromone Treatments. Journal of the American Veterinary Medical Association, 237, 624-626.

https://doi.org/10.2460/javma.237.6.624 